\title{
Research on Indexing Systems for Enterprise Credit Evaluation in B2B
}

\author{
Jinbing $\mathrm{Ha}^{\mathrm{l}}$, Yingjie Wang ${ }^{2}$ \\ 1 School of Economics and Management,Nanjing University of Science and \\ Technology,Nanjing 210094, huwenbin@nuaa.edu.com, \\ 2 School of Economics and Management,Nanjing University of Science and \\ Technology,Nanjing 210094,qyx0955@sina.com
}

\begin{abstract}
Electronic commerce depends on credit system much more than traditional commerce. Credit problem becomes the bottleneck in the development of electronic commerce. Since it is the research basis and object for wholly credit evaluation, how to design the Indexing system of enterprise credit evaluation in $\mathrm{B} 2 \mathrm{~B}$ is very important. The paper tries to establish the Indexing system with consideration the characteristic of online business and online transactions. Hypotheses for enterprise credit evaluation for B2B are discussed. The indexing system of enterprise credit evaluation in B2B is developed including Offline Static Indexes and Online Dynamic indexes. The two factors which impact on online evaluation weights are then proposed.
\end{abstract}

\section{Introduction}

\subsection{Related Research}

Traditional credit evaluation Indexing systems include " $5 \mathrm{C}$ " Indexing system, "5P" Indexing system and LAPP Indexing system. Traditional credit evaluation methods include $5 \mathrm{C}$ and the comprehensive evaluation which based on 5C method developed and widely use [1].Generally key factors are the following five indexes: Character, Capital, Capacity, Collateral, and Condition. 5P means Personal, Purpose, Payment, Protection, and Perspective. 5P reclassify 5C elements, but lack of quantitative analysis [2]. LAPP means Liquidity, Activity, Profitability, and Potentiality [3].However, in china the enterprise credit evaluation and management is still at an early stage, the research was relatively small.

Since 1990 s, along with the rise and popularity of e-commerce, Enterprise credit management theory and credit evaluation to be further developed. Viktor proposes the collective credit in the network environment and the concept of personal credit,

Please use the following format when citing this chapter:

Ha, J., Wang, Y., 2007, in IFlP International Federation for Information Processing, Volume 25l, Integration and Innovation Orient to E-Sociely Volume 1, Wang, W. (Eds), (Boston: Springer), pp. 24l-250. 
and gives the quantitative method. Dong Huynh and others made a business credit evaluation model called FIRE. Mui's research emphases on the credit evaluation model in electronic business transactions. The Web-based online reputation management system is a reputable management tool that the number of e-commerce websites use of. It helps to build the online trust. Reputation Research Network makes the reputation management system as a major study object, conducted a series of studies. R. A. Malaga points that the existing reputation management system has six aspects problem, and proposed a number of solutions. C. Dellarocas identified two types of the system fraud: feedback unfair and sellers of discrimination behavior, and made subject to two mechanisms: controlled anonymity and cluster filtering, to eliminate or reduce the negative influence. C. Dellarocas takes the eBay's reputation management system as example, through establishing the mathematical model to analyze the economic efficiency of the reputation management system.

And there is still a certain gap between home and abroad. Above all kinds of domestic and foreign enterprises credit evaluation research, credit evaluation mainly through financial ratio analysis, that the selection of a number of financial indicators allocated to different weights and through the various methods of scoring indicators, hence the reputation of the enterprise credit. These credit evaluation methods are not fully applicable for our enterprise credit evaluation in B2B.

\subsection{Importance of Enterprise Credit Evaluation in B2B}

In the world of e-commerce to flourish, bring opportunities for Chinese enterprises to enable them to face challenges. It is relatively easy to establish a hard environment, while improving the soft environment is difficult.

Compared with the traditional business, e-commerce on the credit requirements are higher, and the development of e-commerce must enhance credit. Online transactions have $\mathrm{B} 2 \mathrm{~B}, \mathrm{~B} 2 \mathrm{C}$ and $\mathrm{C} 2 \mathrm{C}$ three models. $\mathrm{B} 2 \mathrm{~B}$ model which is the best development in online transactions, because of the relatively high amount of the transaction, the risks are great. there was an urgent need to establish a scientific and effective Indexing system of Enterprise credit evaluation in B2B.

\section{Hypotheses for Enterprise Credit Evaluation in B2B}

This paper established Indexing system of enterprise credit evaluation in B2B (shown in the Fig.1) has two hypotheses: 


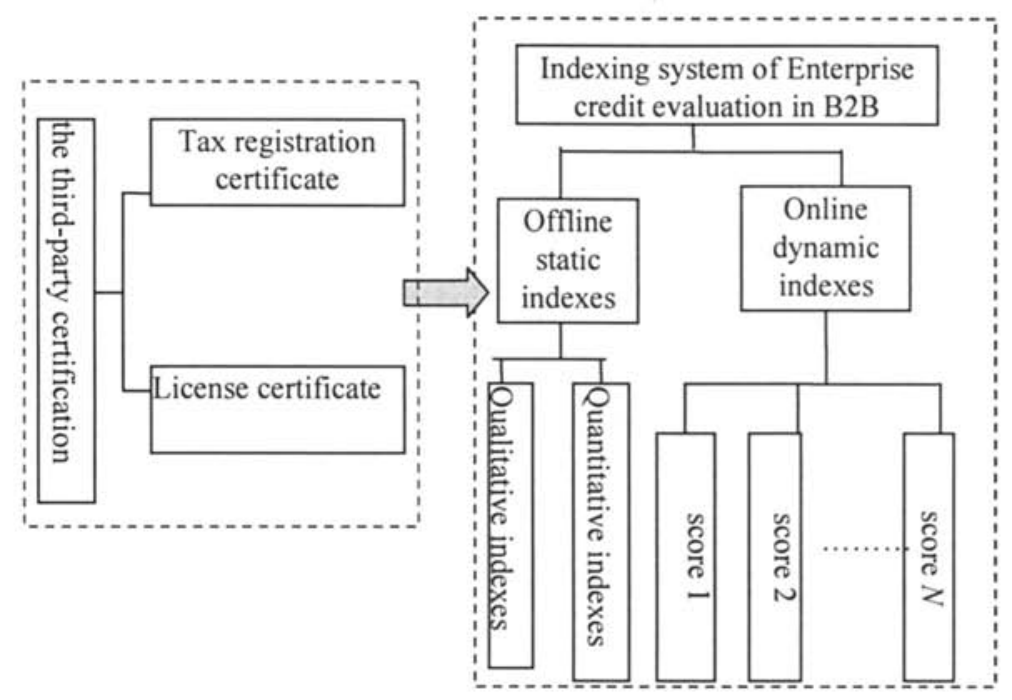

Fig.1.Indexing system of enterprise credit evaluation in B2B and two hypotheses

1) B2B website itself has a good reputation;

2) Online enterprises through third-party certification in the field.

In this paper we suppose B2B website itself has a good reputation, the information provided is true and effective. Second, to assess the situation before the credit evaluation should verify the legitimacy and authenticity of online business. In this Indexing system of Enterprise credit evaluation in B2B, through third-party certification provided by the Registry to obtain registration information, the virtual environment is real enterprises, and enterprises in the Indexing system of Enterprise credit evaluation in B2B as a hypothesis for online transactions.

The third-party certification according to in basic information submitted online request enterprise fax business license and certification of the authorization of attorney. Through local Business Information Inquiry System ask the enterprise made real and the registration of Companies to register relevant information. Through check the tax registration certificate and license certificate given to prove authenticity. Not through third parties authentication, the business will not have access to accredited enterprise credit evaluation in B2B system.

\section{Indexing system of Enterprise Credit Evaluation in B2B}


Indexing system of enterprise credit evaluation in B2B is on-line business credit management system. It followed the establishment of the general management system to improve the circulation pattern: Plan-- Do --Check -- Action continuous improvement model, the PDCA model shown in the Fig.2.

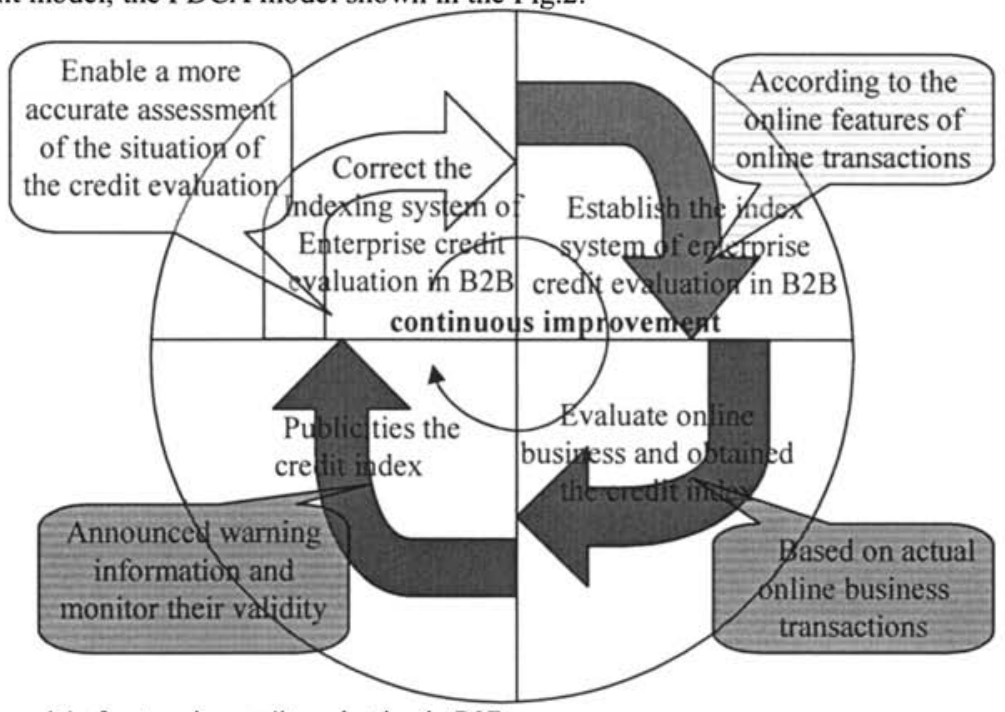

Fig.2.PDCA model of enterprise credit evaluation in B2B

Indexing system of enterprise credit evaluation in B2B in which continuous improvement model, the corresponding steps: Plan--According to the online features of online transactions, established the Indexing system of Enterprise credit evaluation inB2B; Do--based on actual online business transactions, using the Indexing system of Enterprise credit evaluation in B2B evaluate online business and obtained the credit index; Check--publicities the credit index and monitor their validity. At the same time, announced warning information; Action--According to a specific implementation, correct the Indexing system of Enterprise credit evaluation in B2B that enable a more accurate assessment of the situation of the credit evaluation. This paper will be the establishment of Indexing system of enterprise credit evaluation in B2B in offline state enterprise and online transactions for both state examination considerations. The following two sections will be selected on two categories of indexes.

\section{Offline Static Indexes to Enterprise Credit Evaluation in B2B}

\subsection{Offline Static Qualitative Indexes}

Offline static qualitative indexes main line of business as a true indicator of the operating entity of 
society tour inspected the main external factors and the quality of enterprises.

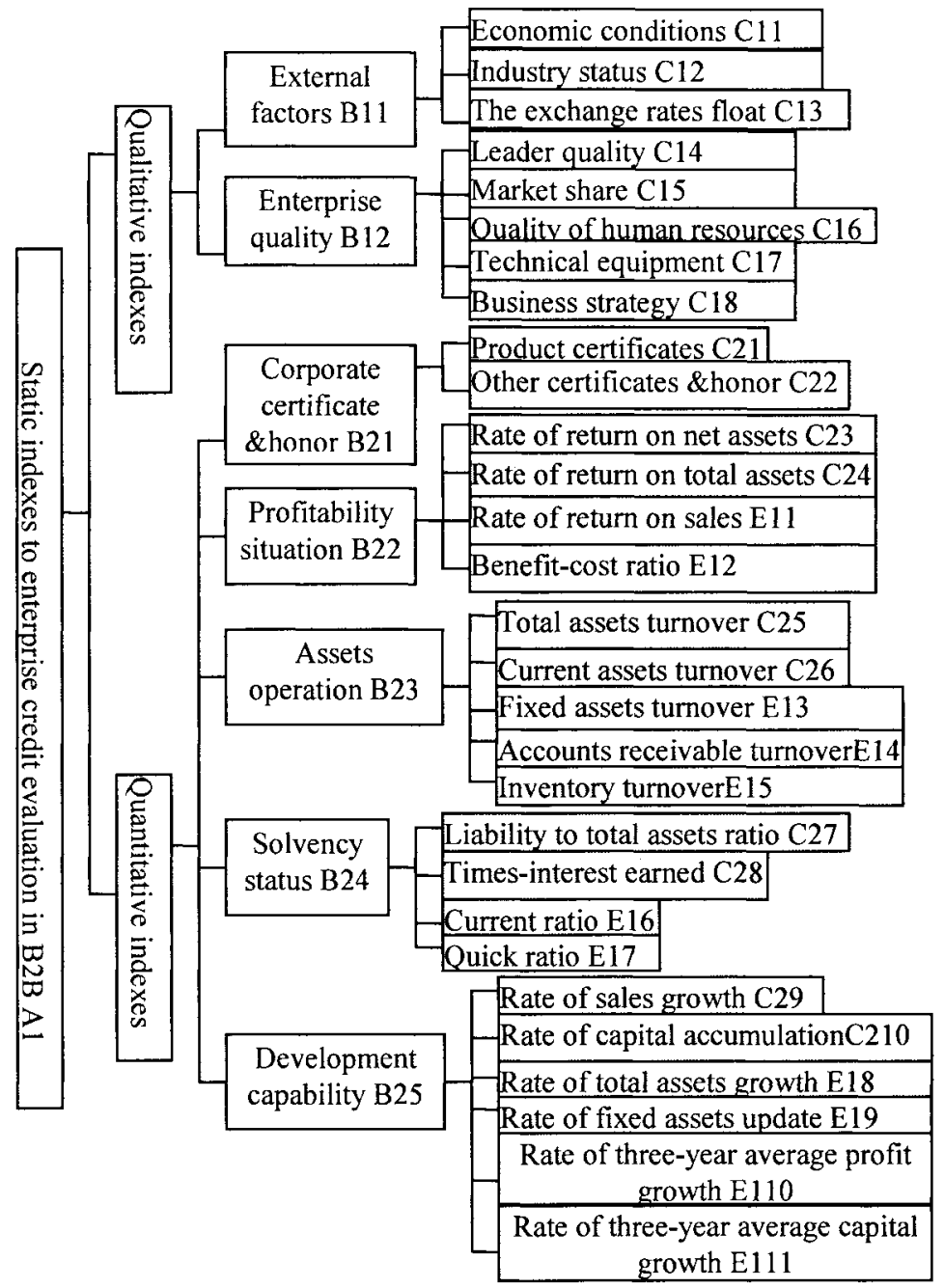

Fig.3.static indexes to enterprise credit evaluation in B2B

1) External factors

In the development process, external factors have an important role to play. The Indexing system inspected by the main external factors, including economic conditions, industry status, the exchange rate float.

2) Enterprise Quality

Besides external factors, enterprise quality is more important factor affecting Enterprise credit evaluation in B2B. The main indexes of the quality of the enterprise system include leader quality, market share, quality of human resources, technical equipment, and business strategy. 


\subsection{Offline Static Quantitative Indexes}

Quantitative indexes of Enterprise credit evaluation in B2B need to consider static line is the corporate certificate honor, profitability situation, assets operation, solvency status and development capability [4]. Static indexes to enterprise credit evaluation in B2B is shown in Fig.3.

1) Corporate certificate and honor. The target selected for the honorary certificates to enterprises is the accumulated operating offline credit extended to the Internet.

(1) Product certificates. It provides online transactions a certificate to the product including the product quality, specifications and other information. (2) Other certificates \&honor. In other areas, the honor or certificates (such as bank accounts to prove that open an account, certificate awarded by the website) can upload to the Internet and be the reference information.

2) Profitability situation. The main indexes used to measure the profitability of the business are rate of return on net assets, rate of return on total assets. Suggestions indexes are rate of return on sales, and benefit-cost ratio.

3) Assets operation. Assets operation indexes reflect not only on business enterprises in using various resources efficiently, but also show that the level of asset management [5]. Bad enterprise operating may lead capital to tension. It will impact the repayment of principal and interest for loans to enterprises. The major indexes for assets operation are total assets turnover and current assets turnover. Suggestions indexes are fixed assets turnover, accounts receivable turnover, inventory turnover.

4) Solvency position. Solvency is the core capability of business credit evaluation. Solvency can be divided into short-term solvency and long-term solvency. The key indicators of Solvency position that used to measure assets and liabilities, including liability to total assets ratio, times-interest earned. Suggestions indexes are current ratio, quick ratio.

5) Development capability. The inspection focused on the growth and sustainable development of business. The growth is the foundation for sustainable development; and sustainable development is the objective requirements of enterprises [6]. No development, there is no future, let alone credibility.

The main indexes for measuring development capability include rate of sales growth, rate of capital accumulation. Suggestions indexes are rate of total assets growth, rate of fixed asset update, rate of three-year average profit growth, rate of three-year average capital growth.

In the Indexing system, offline B2B Online static indexes it is difficult for SMEs to obtain, but the Indexing system will target its consideration, because they can be full-line static indexes, a true understanding of operation and development situation and can be a good illustration of the extent of the online business's credit.

\section{Online Dynamic Indexes to Enterprise Credit Evaluation in B2B}

Online dynamic indexes suggesting that these criteria are objective formed in the course of online 
trading, mainly selected delivery, transport, payment, service and reference. Two different online dynamic indexes are proposed for the seller \& buyer. Online dynamic indexes as in the Fig.4:

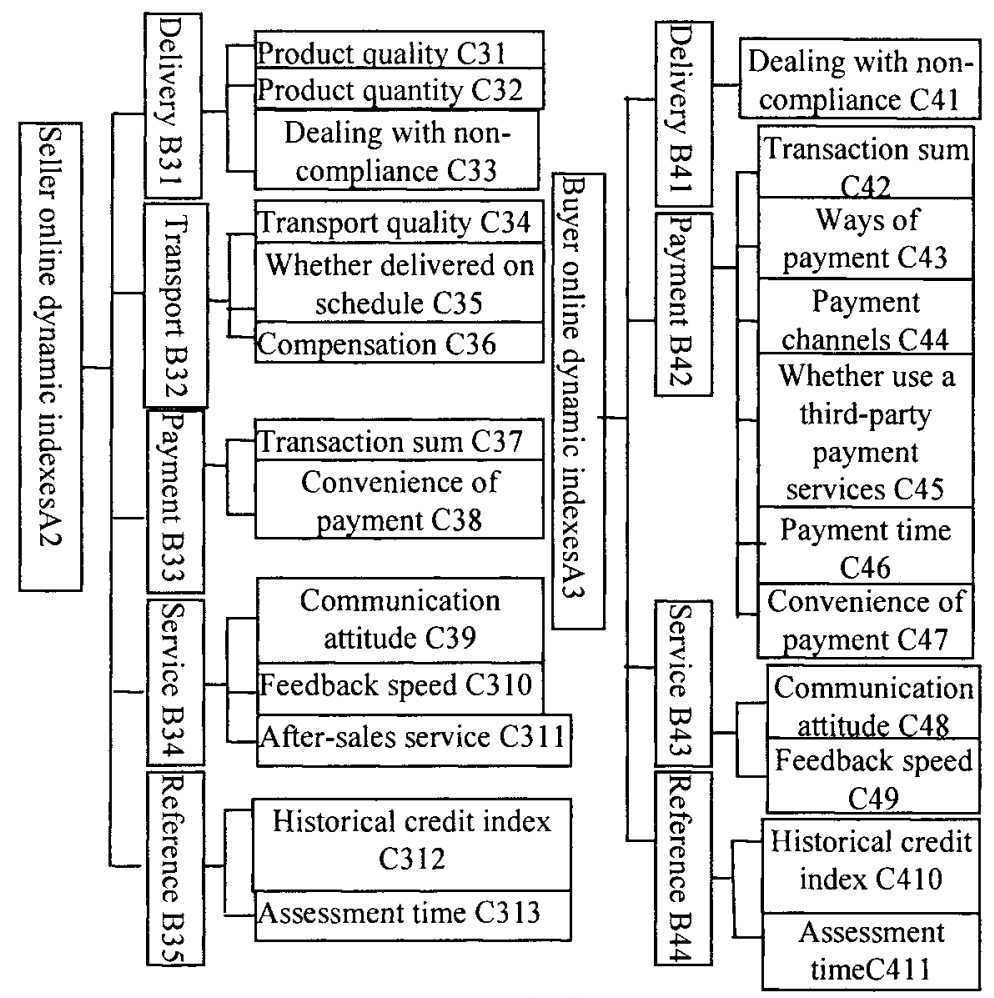

Fig.4.Online dynamic indexes to enterprise credit evaluation in B2B

1) Delivery. In the Indexing system it selects product quality, product quantity and dealing with non compliance three indicators to be evaluated.

(1) Product quality. It mainly indicates whether the seller in accordance with the agreed terms of the Internet to provide the same quality, the same specifications of products, whether the defects, and so on. (2) Product quantity. It means whether agreement with the number of Internet-related cases. If the seller deliberately reduced number of goods with no explanation, and not given the compensation package, which can be regarded as violations, it could greatly affect the index of the Enterprise credit evaluation in B2B. (3) Dealing with non-compliance. At the point of delivery, if goods default (the goods quality or quantity have problem, cancellation of transactions, etc.), how to dealing with these problems.

2) Transport. Transport of goods mainly reflects whether the transport of merchandise on time and the quality of delivery, compensation, and so on. 
It needs to be pointed out that in online transactions, most transport is through thirdparty logistics companies to provide, but the transport of merchandise situation some extent reflect the seller's credit behavior.

(1) Transport quality. It means the quality of goods (expensive, fragile goods) in the transport process of the damage, defects in the normal range is allowed to ignore. (2) Whether delivered on schedule. Whether the seller to deliver goods on time is after the online transactions whether the seller obeys lease agreement on time and makes goods reaching the buyer is located to. (3) Compensation. If a force majeure (natural disasters such as unexpected situation), not on time served, whether the seller to provide satisfactory compensation.

3) Payment. In the Indexing system, payment assessment's object is online transactions capital flows, not including the internal capital flow. The Indexing system mainly chooses the sum of the transaction, ways of payment, payment time, these three-pronged test indexes.

(1) Transaction sum. The transaction amount of funds mainly studies the amount of the online transaction. Different industries should choose different standards for given different coefficient. (2) Ways of payment. There are many ways of payment, in installments, or a one-time payment. (3) Payment channels. Can be made by bank transfer, it can also be a check or cash. (4) Whether use a third-party (such as paypal) payment services. (5) Payment time. The time of payment see about whether the buyer has an extension of payment arrears, and other things else. (6) Convenience of payment. It inspects the diversity and convenience of payment.

4) Service. Service performance means buyers and sellers' attitude, the paper selected communication attitude, feedback speed and after-sales service three indexes to measure online enterprise service performance.

(1) Communication attitude. Communication attitude is the attitude between the two transactions' communication. Online transactions can use the network to communicate and consultations. After the transactions, the two sides evaluate each other's communication attitude. (2) Feedback speed. Feedback speed is the speed of feedback after the two transactions raise questions. Online transaction process on the parties to the transaction may raise product characteristics, means of transport, form of payment and other questions. At this time feedback speed will become an online transaction indexes. (3) After-sales service. After goods sold, how about after-sales service, were offered technical support, maintenance and other after-sales service.

5) Reference. Reference mainly refers to data that provide information as reference while online transaction happening.

(1) Historical credit index. A credit history index party to the transaction is the current credit index, the credit evaluation results of the current Indexing system. (2) Assessment time. The time that Online business to participate in the Indexing system of Enterprise credit evaluation in B2B means whether or not to pay on time online credit evaluation system, and long-term honesty and trustworthiness. In this paper online business that participates in evaluating the credit of enterprises are willing to deal honestly. Therefore into online business credit evaluation system more time, the corporate credit rating higher. 


\section{The Two Factors Impact on Online Evaluation Weights}

After online transactions, according to the performance of the other parties to the online transaction in the transaction process and after the transaction, the other side assesses its credit evaluation points. At the same time, the valuators credit index will affect the credibility of their evaluation; online credit evaluation time distance will also affect the validity of the evaluation.

Therefore, when concentrate the dynamic index score, it should also consider two factors that influence online transactions parties credit evaluation.

1) The valuators credit index. The valuators credit index is the last score in Indexing system of Enterprise credit evaluation in B2B. This reference is a reflection of the credit valuators' credit degree. The higher credit index valuators got the more credibility the evaluation is. So valuators credit index to some extent reflected the valuators credit index credible.

2) Online credit evaluation time distance. Online credit evaluation time distance will also affect the validity of evaluation. Evaluation of a short time, that is relatively new credit evaluation will be better able to explain the recent evaluation of the enterprise credit, This assessment is more effective; evaluation of the long time show an earlier time enterprise credit, the evaluation of the effectiveness is poorer than new credit evaluation.

\section{References:}

1. C. Gomez and A. Careening, "Business credit scoring", Journal of Business Credit, Mar 2001,103,3.

2. S. Standifird, "Reputation and ecommerce: eBay auction and the asymmetrical impact of positive and negative ratings", Journal of Management, 2001,27(3):279295

3. P.Resnick, R.Zeckhauser,E.Friedman and K. Kuwabara, "Reputation systems", Communicationsof the $A C M, 2002,43(12): 45-48$.

4.E.I.Altmam, F.Varetto, "Corporate Distress Diagnosis: Comparisons Using Linear Discriminant Analysis and Neural Networks (the Italian Experience)", Journal of Banking and finance, 1999(18):505-529

5.E. I. Altman,R. G. Haldeman, P. Z. Narayanan, “Analysis: A New Model to Identify Bankruptcy Risk of Corporations", Journal and Finance, 1997(1):29-54

6.J. Ohlson, "Financial. Rations and the Probabilistic Prediction of Bankruptc", Journal of Accounting Research, 1980(2):109-130

7.S. Viktor, Grishchenko, "Redefining Web-of-Trust: reputation, recommendations, responsibility and trust among peers", Ural State University, Institute of Physics and Applied Mathematics, 1999,159-166

8. T. Dong Huynh, Nicholas R. Jennings, Nigel R. Shadbolt. "FIRE: An Integrated Trust and Reputation Model for Open Multi-Agent Systems", School of Electronics and Computer Science, University of Southampton,UK,2001.147-151 
9.Lik Mui, "Computational Models of Trust and Reputation: Agents, Evolutionary Games, and Social Networks", Electrical Engineering and Computer Science, 2002(6): 112-124

10.M. Fisher, "What is the Right Supply Chain for Your Product", Harvard Business Reviews, 1997(4):112-116

11.S.Standifird, "Reputation and e-commerce: eBay auction and the asymmetrical impact of positive and negative ratings", Journal of Management, 2001,27(3):279295

12.P. Resnick, R. Zeckhauser, E. Friedman and K. Kuwabara, "Reputation systems", Communications of the $A C M, 2002,43(12): 45-48$.

13.J. H. Cui, "China's e-commerce development of the credit system to explore", modern shopping malls, No. 471 overall, 2006 (6): 134-135

14.J. Zhen, "China's e-commerce credit system construction", Dalian Maritime University Journal, Volume 5, No. 2, 2006 (6) : 73-76

15.J.Wang and $\mathrm{G}$. Wu, "Electronic assessment of goodwill", agricultural information network, 2006 (4) : 66-68

16.Z. H.Yan, S.X. Guan and J.N. Mi, "Based on the model of B2B e-commerce trust theoretical research", research management, Volume 25, No. 2, 2004 (3) : 76-81

17.W. Yang, "Research on Enterprise Credit System and Design, South China University of Technology", a master's degree thesis, 2004 (3)

18.Y. Yan, "E-commerce trust management realized", Wuhan Institute of Science and Technology Journal, Vol 16, No. 6, 2003 (12) : 90-94

19.G. Q. Yu and G.X.Song, Tourism means of e-commerce trust building and economic issues to explore, 2005 (11): 118-121 